\title{
Construction Method of Salar Traditional Settlement
}

\author{
Haichen Zheng ${ }^{1,2, ~ a, ~ W e n y u ~ Z h a o ~}{ }^{1,2, b}$ and Hongbin $\mathrm{Ma}^{1,2, \mathrm{c}}$ \\ ${ }^{1}$ School of Civil Engineering, Northwest Minzu University, Lanzhou 730030, China; \\ ${ }^{2}$ Key Laboratory of New Laboratory of New Building Materials and Building Energy-saving of Gansu, \\ Lanzhou 730030, China, \\ a593224467@qq.com, b565073924@qq.com, ‘327358484@qq.com
}

Keywords: the Salar nationality; morphological characteristics of settlement; space construction; residential building

\begin{abstract}
The Salar nationality believes in Islam, and the clansmen mainly live in Xunhua Salar Autonomous County of Qinghai Province and Dahejia, Baoan nationality and Dongxiang Salar Autonomous County, Jishishan, Gansu Province. The construction of many traditional settlements of the Salar nationality is ingenious and diversified, which not only adapts to nature and local climate, but also combines with custom and belief. With the implementation of the 13th Five-Year Plan, it is necessary to carry out some basic research on the traditional local settlement prototype "to integrate modern elements, protect and carry forward the traditional excellent culture and continue the historical context" in the construction of new town. Based on field investigation, this paper analyzes the morphological characteristics, space construction and residential building of Salar traditional settlement. The prototype construction method of traditional settlement is studied to explore the formation and development law of settlement so as to provide reference value for the future urban and rural construction in this area.
\end{abstract}

\section{Introduction}

The Salar nationality believes in Islam, and the clansmen mainly live in Yellow River valley of Xunhua Salar Autonomous County in Qinghai Province and Dahejia, Baoan nationality and Dongxiang nationality Salar Autonomous County of Jishishan in Gansu Province. The construction of many traditional settlements of the Salar nationality is ingenious and diversified, which not only adapts to nature and local climate, but also combines with custom and belief. With the implementation of the 13th Five-Year Plan, the urbanization and new countryside construction in ethnic areas have been further promoted. Therefore, it is necessary to carry out some basic research on the traditional local settlement prototype and space building "to integrate modern elements, protect and carry forward the traditional excellent culture and continue the historical context" in the construction of new town, so that the new urban settlement space can have the sense of national identity and belonging.

\section{History of the Salar Nationality}

In the late Yuan Dynasty, Ga lemang and his brother A hemang who lived in the Salar tribe of Turkmenistan in Central Asia could not bear the slander, exclusion and strife of the tribal aristocrats, and led the people to migrate to Xunhua, Qinghai after trudge. The Salas in Gansu mainly immigrated from the streets of Jiezi, Yamen, Xigou, Baizhuang, Qingshui, Mengda, Caotan Dam and Tasapo in Xunhua. "Gongbei" constructed by Ga lemang and his brother A hemang is still preserved in Jiexi, Xunhua. There is a spring called "Camel Spring" near "Gongbei". As is shown in Fig.1," the Camel chronicle" records the story of the Salar ancestors who immigrated from long distance. Samarkand lived with the surrounding Tibetan, Hui, Han, Mongolian and other ethnic groups, and developed into the current Salar nationality. The Salar people call themselves "Salar". They have their own language but have no character. Chinese is commonly used in the Salar nationality [1]. 


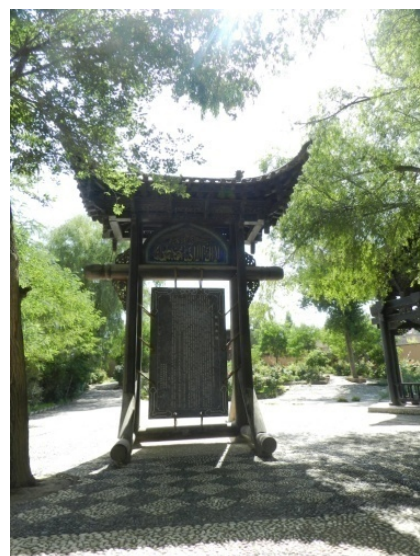

Fig.1 Camel spring chronicle

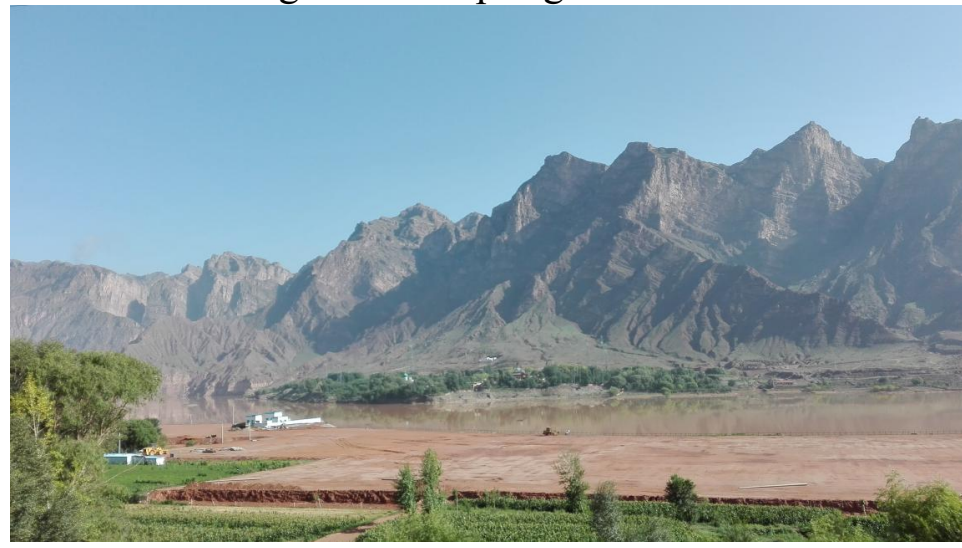

Fig.2 The Yellow River flows through the canyons beside the village

\section{Morphological Characteristics of the Salar Traditional Settlement}

Morphology is the expression form of things under certain conditions. Archaeologist Gordon Willey defined settlement morphology as "the way in which humans treat themselves on the ground where they live." It includes houses, the layout of houses, and the shape and treatment of other buildings related to the life of the community. Affected by natural environment, social and economic level and local multiculturalism, the traditional local settlement of the Salar nationality has the inclusive characteristics and harmony without uniformity in village location, layout and construction.

\subsection{The Spatial Form of Settlement Under the Influence of Natural Environment and Selection}

Settlement has the meaning of "location", and settlement morphology is influenced by the natural environment in a certain area [2]. The water resources of natural environment are the decisive factors for the survival of rural settlements. The carrying capacity of water resources determines the location and scale of settlement. Land resources are the most important means of life and production of farmers, which directly affect the location, scale, density and spatial distribution of settlement groups [3].

The Salar nationality mainly lives in Xunhua of Qinghai Province and Dahejia, Jishishan of Gansu Province, which are all located in the upper reaches of the Yellow River and adjacent to the Yellow River Valley. In this area, the river flows through the canyons beside the village, which lays the framework for the overall morphology of the village in Fig.2. The high mountains on both sides of the strait are towering, and the basins are long and narrow, high in the south and low in the north in Fig.3. The area has warm climate, rich land, and sparse population. Although it is far away, both water and soil are similar with their hometown. Therefore, it is an ideal home for the Samarkand refugees. According to a legend of the Salar nationality, the relationship between Ga lemang and the king has soured. Therefore, he led a white camel carrying water and earth and the Koran, and left Samarkand with his troops. They migrated eastward to Xunhua, where the land is smooth, the meadow is vast, 
and the forest is wild. The water and soil here are totally the same with their hometown, and they settled here [4]. Limited by natural conditions, the Salar ancestors lived in plain and open valleys near water sources and flat banks and dams. The tried to avoid low-lying areas, mountains and water gullies, and developed into a small piece of settlement area in Fig.4.

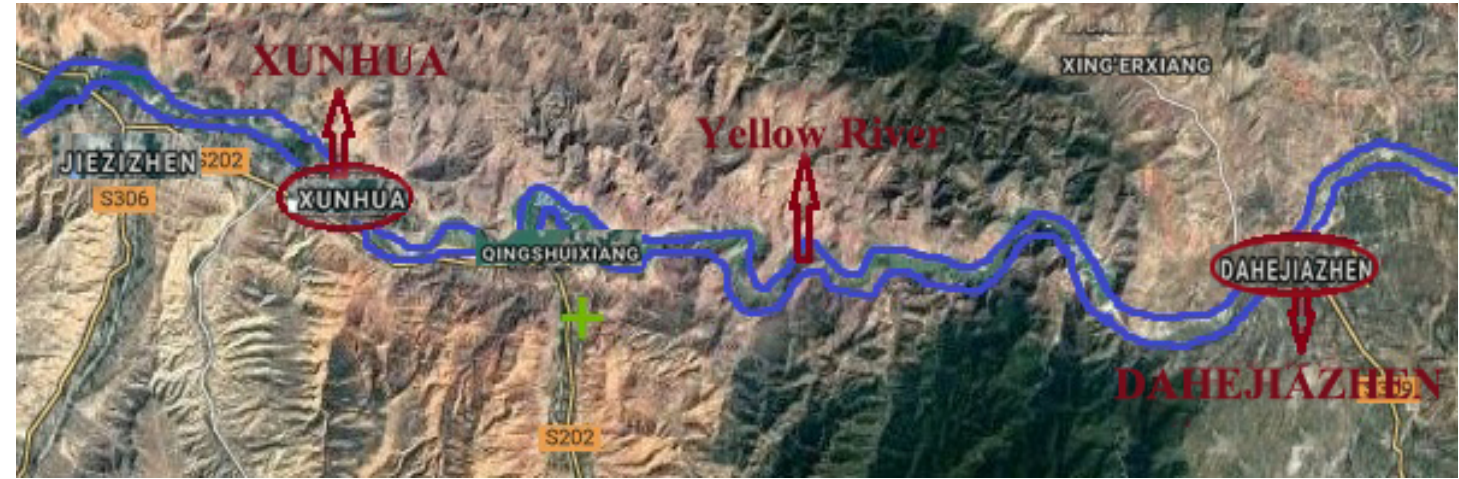

Fig. 3 Xunhua and Dahejia adjacent along the river

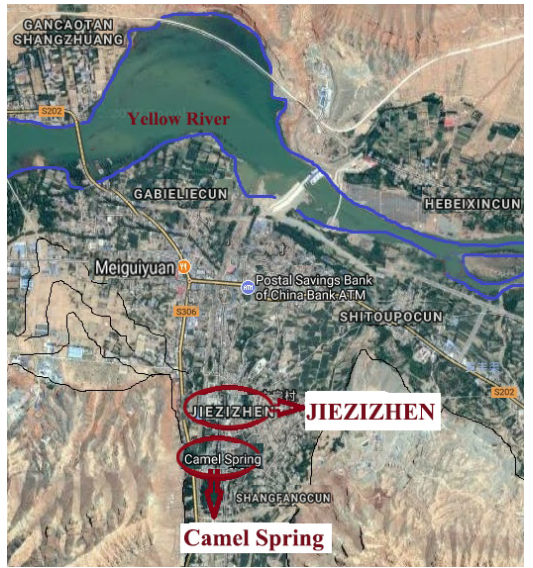

Fig. 4-1 Jiezigu Town

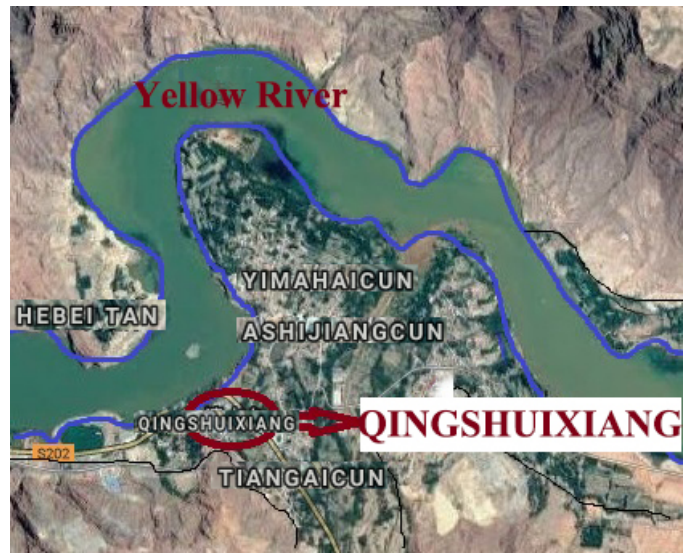

Fig. 4-3 Qingshui Village

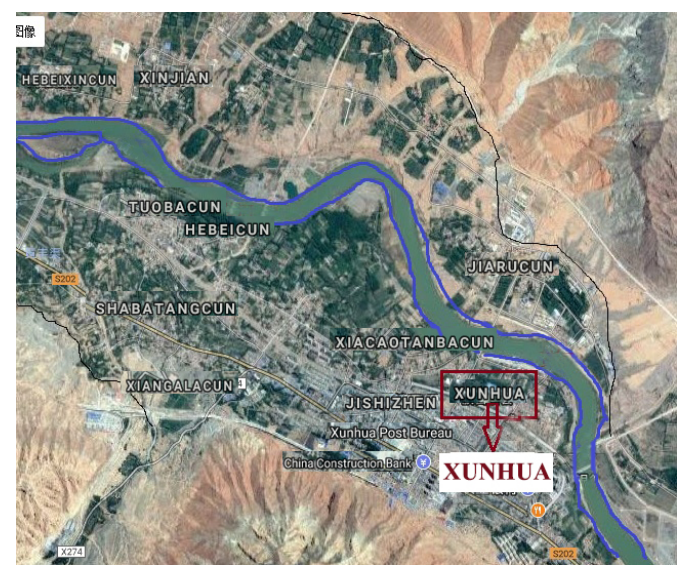

Fig. 4-2 Xunhua County

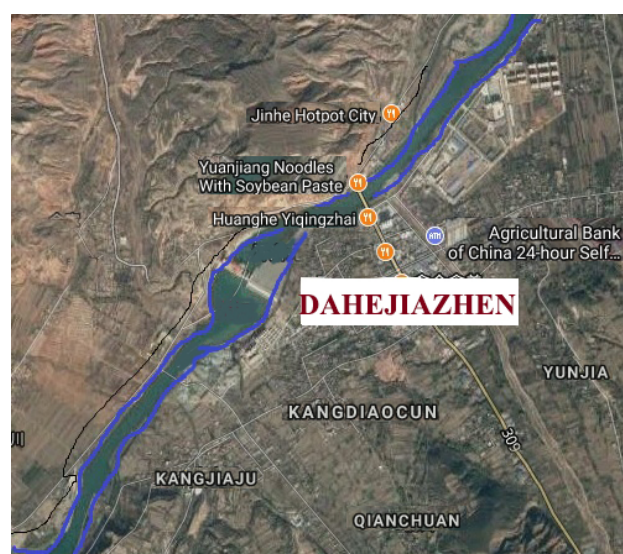

Fig. 4-4 Dahajia

Fig.4 Open valley and flat dam (Network satellite screenshots)

\subsection{Settlement Spatial Schema at the Cultural Level}

The main body of a village is human, and the morphology of the village reflect people's consciousness and spiritual desire. Compared with physical environment, the social organization structure of the village is recessive. Despite of the slow change, it is a factor with profound significance [5].

The Salar is a nationity with strong clan consciousness and religious faith. The traditional villages formed by blood relationship and religious relations often show significant closeness, stability, continuity of tradition and strong belief consciousness. 
The most obvious influence of kinship and religious belief on the spatial structure of the village is that the settlement morphology is block mass schema of living in a compact community beside temples in Fig.5. This settlement morphology is often centered around one or more core bodies of the settlement villagers, relatively stable introverted group space with concentrated layout. The scale is small, and there are about dozens of households. The settlements are generally formed spontaneously or by geographical conditions. Mosque is the core in the single core block mode. In the multi-core block model, the main core is the mosque. The other core body may be the village committee, Gongbei and waterlogging dam bleachery. This multi-core spatial structure is formed due to the expansion of the settlement population from the division of the group or the presence of the settlers in Fig.6 [6].

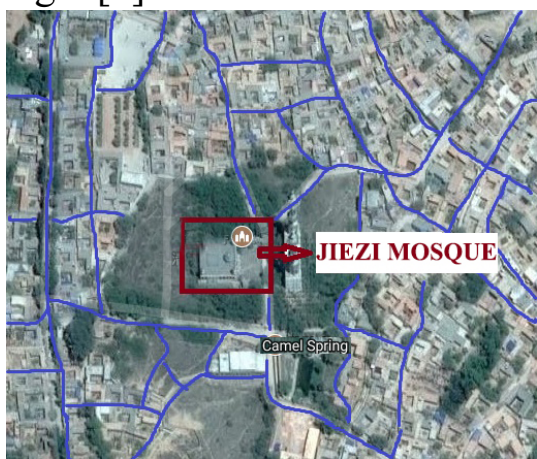

Fig.5-1 Jiezigu Town

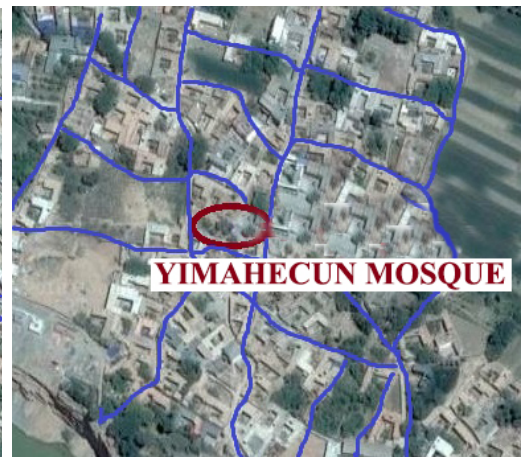

Fig.5-2 Yimahai Village

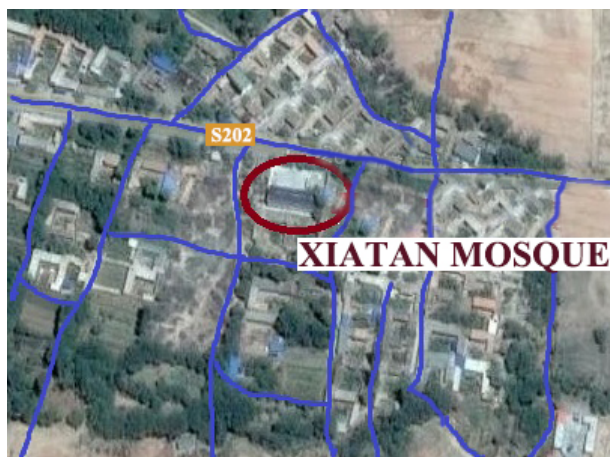

Fig.5-3 Xiatan Village

Fig.5 The Salar village where the Salar people live beside the temples and road skeleton system

(Network satellite screenshots)

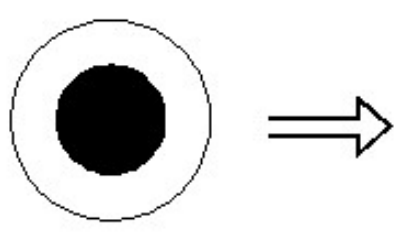

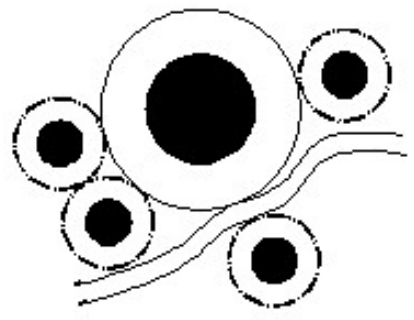

Fig.6-2

After the village development, the residents separated out, and lived around the new temple and Gongbei village committee, forming a multi-core structure The mosque remained the

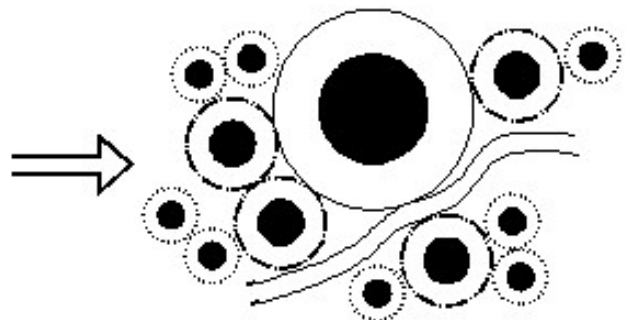

Fig.6-3

The village continuously expanded and separated, forming the structure with multiple core blocks. The mosque was still the spiritual center of the whole village. the only public place in the village. spiritual center of the whole village.

Fig.6 Schematic diagram of core block structure

\section{Building Method of Settlement Space}

Although the morphology of the Salar traditional settlement is not a rigorous geometric network, the material space appearance and the deeper humanity background contain the clearer concept. We can recognize the settlement space construction method at three levels of boundary, center space and laneway network.

\subsection{Boundary}

Boundary marks the maximum scope of the collective life of the settlement community, and it lays the meaning of a village. The traditional settlements of the Salar nationality mostly take the natural landscape as the boundary condition of the village. Rivers, slopes and mountains with linear and 
vertical barriers can be used as a part or all of village boundary in Fig.7. There are also some symbolic borders, such as big trees at the entrance of the village and small shops along the road in Fig.8. The boundary of the village is an ever-changing boundary. As the village changes, the boundaries continuously expand, and the original boundaries may become the later interface along street. The existence of the village boundary makes the village delimit the area that people need from the natural environment, thus leading the placeness of the village.

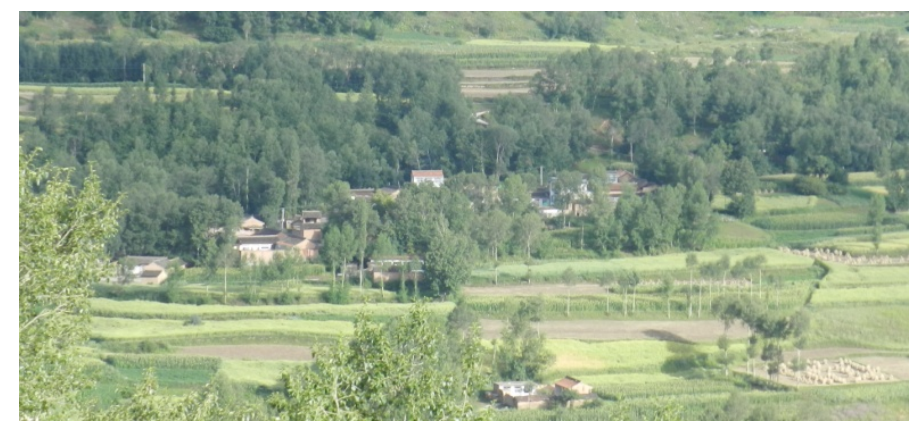

Fig.7 Natural landscape as the boundary

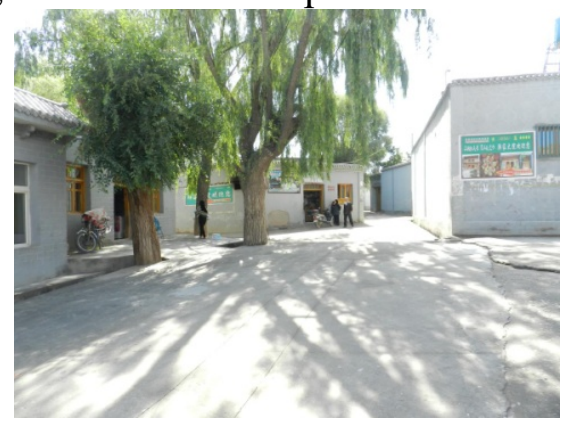

Fig. 8 Big trees and shops at the entrance of thevillage as the boundary

\subsection{Center, Public Place and Mosques}

The reason why settlements can exist as a community and continue is that the inner strength plays an important role [7]. In the Salar area, the mosque is the place with the the point with the "central" meaning and "place" spirit. Square in front of the temple in Fig. 9 is a rare open area in the village. In addition to mosques providing spiritual centers to the public, there are many rural public places, such as village committee, market square, and waterlogging dam tanning yard. People chat, sing the folk song, and exchange all kinds of information.

Mosque is an important organizational facility for Islam and regarded as "The House of Allah" and the soul of religion by Muslim. The Islamic Spirit permeates the mind of Muslim with mosque as the media [8]. Muslim worship Allah and reach the higher authorities through mosque [8]. Influenced by the mosque architecture in Central Asia, the early mosques in the Salar nationality belong to the Islamic style of Central Asia, such as Jiezi Muslim Temple in Jiezi Ancient Town in Fig.10. Later, mosques have Chinese characteristics combined with the Han culture. Most mosques have become the Islamic-style mosques with Chinese characteristics in Fig. 11.
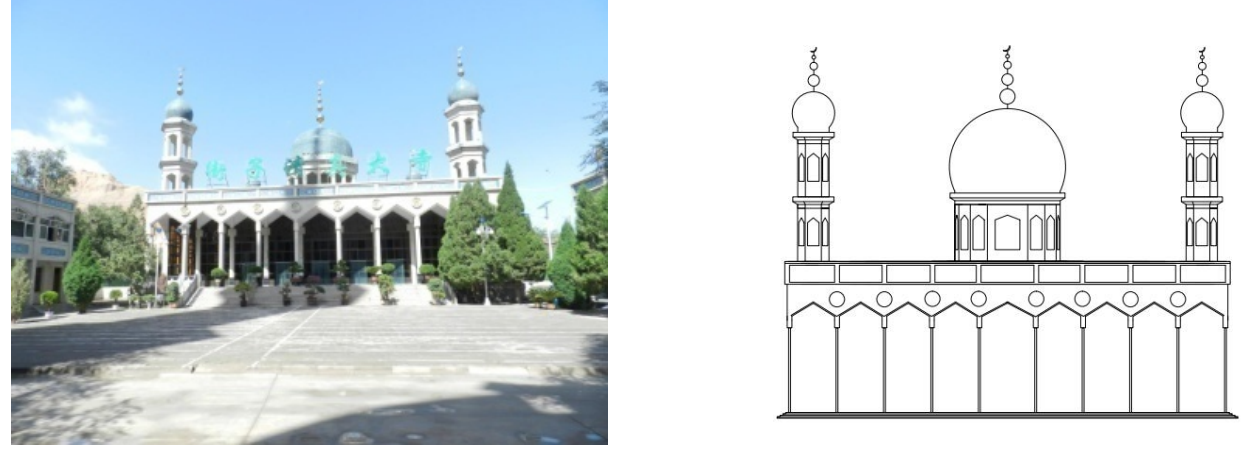

Fig.9 Square in front of the temple

Fig.10 Jiezi Muslim Temple with Central Asian style 


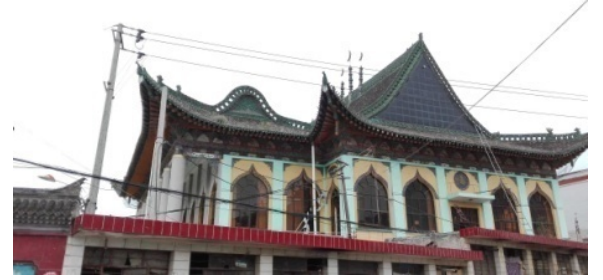

Fig.11 Salar temple with Chinese style

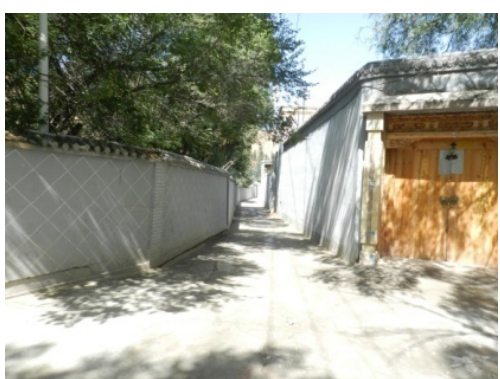

Fig.12 A narrow and winding street

\subsection{Street Network}

The boundary provides territory, and the center provides cohesion. Roads and streets link the boundaries, nodes, centers, and a large number of houses, and form an integral structure. In the formation and extension process of road system, there is no fixed mode, which is convenient and practical combined with the environment. Streets are formed on the basis of roads. With the increasing residential buildings and other types of buildings on both sides of the road, the building density becomes higher, forming closed street space on both sides.

The road layout of the early Salar traditional settlements can be organically combined with the terrain. The backbone of regular road network is supported by primary roads and branches vertical or parallel to contour line. The herringbone paths lead to the front and back of houses in Fig.5. The streets and alleyways used in daily life are narrow and tortuous in Fig.12, and the roads to the outside world are straight and smooth. The depressed space of high walls and narrow alleys is alleviated by twists and turns. In spite of the narrow streets, the nodes in the space are "squeezed" by conceding distance, turning and encircling, and some comfortable space for interpersonal communication are built. The streets have vitality, houses have recognizability, and communication has affinity in Fig. 13 and Fig. 14.

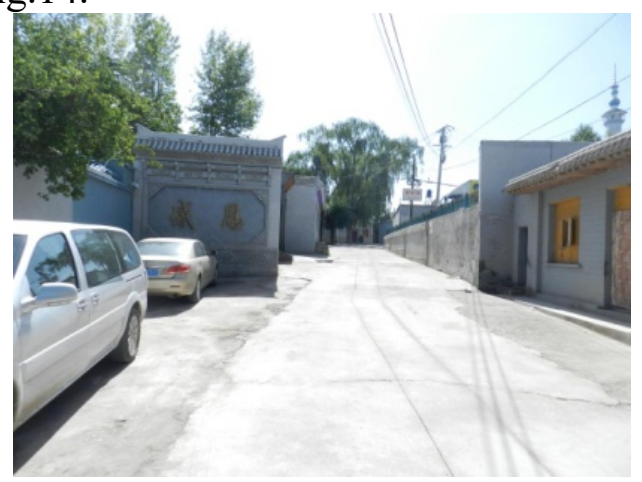

Fig.13 Village entrance

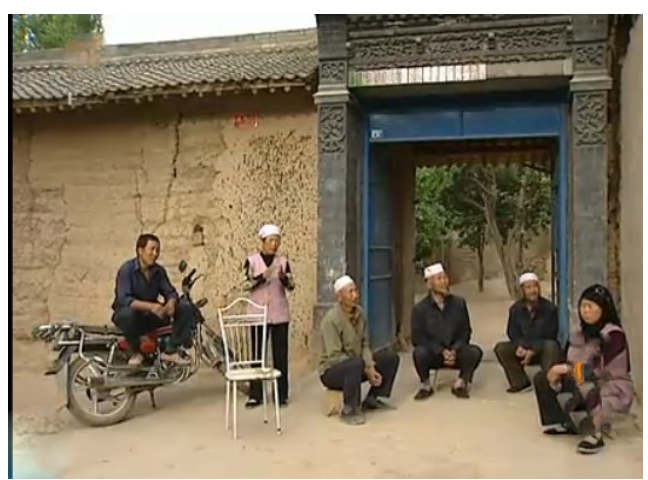

Fig.14 Small open space in front of the house

\section{Residence Construction}

The Salar nationality lives in a compact community, forming their small or large areas. The layer of the courtyard is triple courtyard, namely, principal house facing south. The houses are mainly two-floor fence buildings, eastern wing-room facing east, and western wing-room facing west. The wing-rooms are mainly in the form of "Hubaotou", namely, concave form. The middle one, or three, is separated from the eaves. The residential courtyard of the Salar nationality is larger, where fruit trees, flowers and vegetables are planted in Fig.15 and Fig. 16.

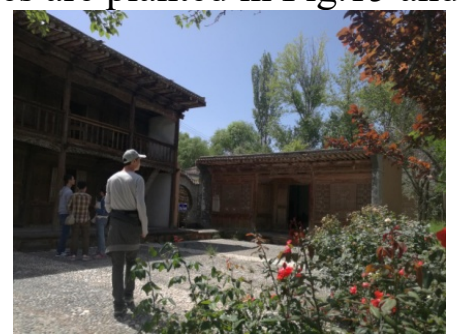

Fig.15 The traditional residence

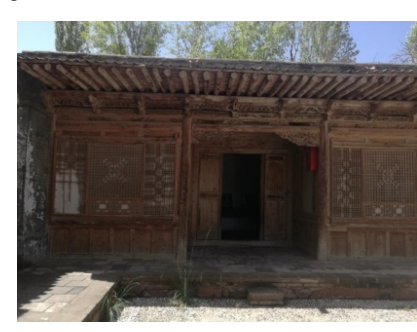

Fig.16 "Hubaotou" 


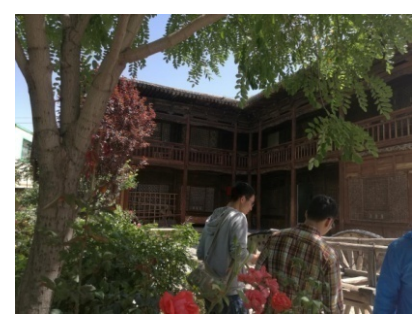

Fig.17 Ancient residential fence building

Courtyard of the Salar nationality

The ancient fenced buildings of the Salar nationality absorb the culture of the Han nationality, the Tibetan nationality, and Islamic cultures, and have the characteristics of architectural style in Ming and Qing dynasties. They were built by people of all nationalities with their wisdom in Fig.17. Fence wooden buildings generally have two floors. The upper floor is bedroom and guest rooms, and the lower floor is warehouse and livestock enclosure. The house structure form is Flat roof building with wooden and mud structure. The frame of the fence wooden building is composed of pine wood. The walls are made of hardwood branches. The two surfaces are mud and the wall is empty. Most doors, windows and pillars of the houses are decorated with various fine designs. The building built by this method can save building materials and reduce the weight of the building body. Meantime, the hollow walls are warm in winter and cool in summer, and the air permeability is good in Fig.18, 19 and 20.

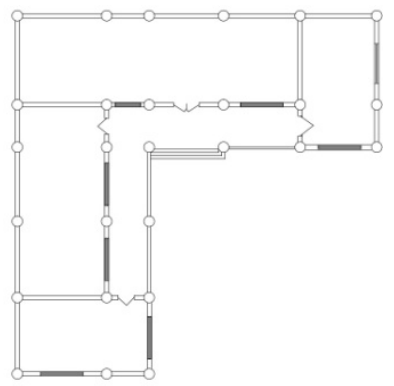

Fig.18 Floor plan of the

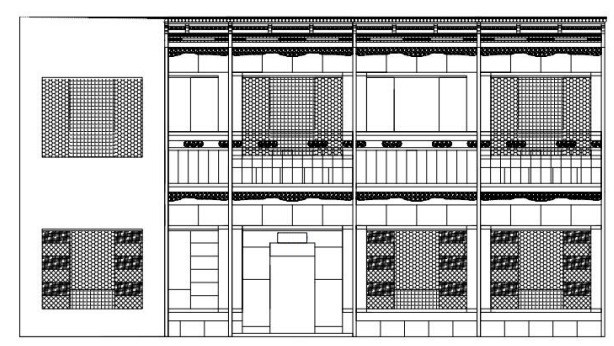

Fig.19 Front elevation of

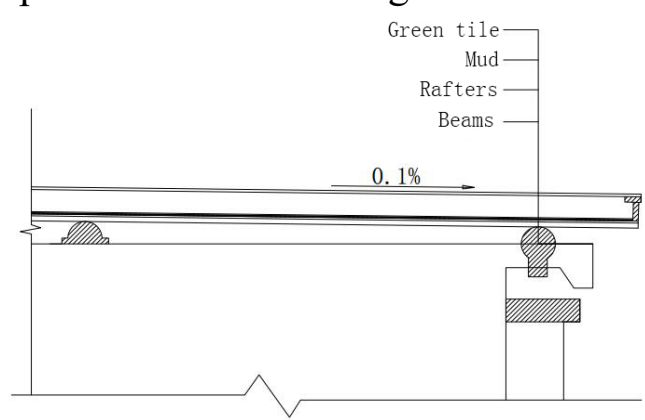

Fig.20 Roof structurelower floor of fence building fence building elevation

The new Salar dwellings inherit the traditional culture. The construction absorbs new style and ideas based on the traditional houses. However, it mainly adopts a flat roof with a civil structure. The residence is stil triple courtyard. The main room is two floors, and faces south, with fence building style. The wing-room is one floor with "Hubaotou" pillar. The gate is the traditional Chinese wood archway with cornices and warp corners. Large wood materials are pine wood, black brick, grey tiles, high hall, big courtyard, and rich ornament in Fig.21, 22 and 23[4]. 


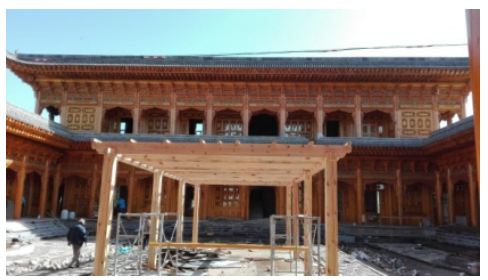

Fig.21 Principal room imitating

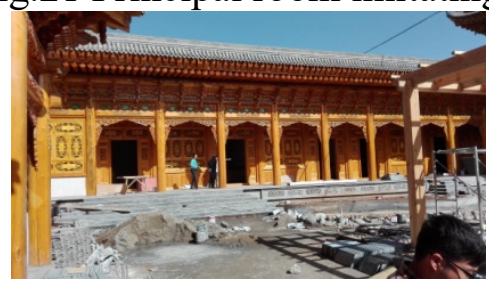

Fig.22 Wing-room with fence building

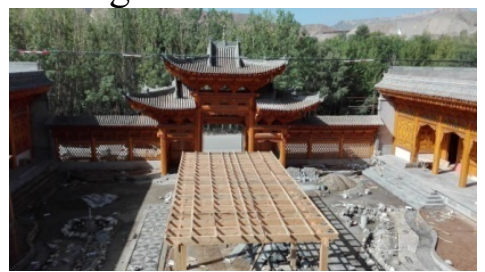

Fig.23 Wooden archway gate

"Hubaotou" pillars

\section{Summary}

Based on the above analysis, it can be seen that the local traditional architecture settlements have formed a harmonious organism with natural environment, technological environment and religious regional culture. The research aims to continue the elements with historical implication, so that the modern settlement architecture can draw its essence and give people a sense of belonging. By exploring its internal characteristics, recording and summarizing the wealth that is disappearing, and drawing lessons from the formation and development of settlements, this paper provides a reference value for the future urban and rural construction in this area.

\section{Acknowledgments}

The project fund is from 2014 National Civil Affairs Commission Scientific Research Project,the project number of which is $14 \mathrm{XBZ} 025$.

\section{References}

[1]. Writing group of General Situation of the Baoan Nationality, et al. the Dongxiang Nationality and the Salar Nationality Autonomous County Jishi Mountain. Nationalities Publishing House, 2008, p.28

[2]. Nan Zhang: Research on the China's Traditional Settlement Morphology as a symbol of Social Structure (Dr,Tianjin University,China2010). p.54

[3]. Ningna Yan, et al. Research on the Construction and Development Strategy of Hui Settlement in Xihaigu Ningxia. China Architecture \& Building Press,2016, p. 117-118.

[4]. Information on: https://baike.baidu.com/item/China salar

[5]. Ling Cai, et al.Traditional Villages and Architecture of the Dong Nationality Settlement. China Architecture \& Building Pres,2007, p.253. 
[6]. Haichen Zheng,Wei Zhang, et al.Analysis on the Traditional Settlement Construction Strategy of the Baoan Nationality. Collected papers of the 17th Annual Academic Meeting of the Chinese National Architecture Society.Vol. 11 (2014) No. 11, p. 11.

[7]. Yun Wang, et al. Spatial Concept in Traditional Settlement Structure. China Architecture \& Building Press,2009, p. 13.

[8]. Weilin Mian, et al. An Introduction to the Islamic Religious System of the Hui Nationality in China. Ningxia People's Publishing House,1997, p. 133.

[9]. Picture source:All pictures are taken on the spot except for the special indication. 